\title{
Ocena zależności pomiędzy występowaniem próchnicy uzębienia mlecznego a jej rozwojem w zębach pierwszych trzonowych stałych
}

\section{Assessment of the relationship between caries in milk teeth and the development of this disease in the first permanent molars}

\author{
Katedra i Klinika Stomatologii Dziecięcej, Uniwersytet Medyczny im. Karola Marcinkowskiego w Poznaniu
}

\author{
DOI: http://dx.doi.org/10.20883/df.2016.5
}

\section{Streszczenie}

Wprowadzenie. Poznanie udziału czynników ryzyka stanowi podstawę dla rozwijania skutecznych metod zapobiegania chorobie próchnicowej zębów tak u dzieci, jak i dorosłych.

Cel. Ocena wpływu występowania choroby próchnicowej w uzębieniu mlecznym na jej rozwój w zębach pierwszych trzonowych stałych u dzieci 7-letnich.

Materiał i metody. Materiał badawczy stanowiła populacja 2138 dzieci (1033 dziewczynek i 1105 chłopców) w wieku 7 lat zamieszkujących miasto Poznań. Przeprowadzone badanie kliniczne polegało na ocenie występowania próchnicy w uzębieniu mlecznym i zębach pierwszych trzonowych stałych. Na podstawie uzyskanych danych obliczono frekwencję i intensywność (puw-z, PUW(6)-z) choroby próchnicowej zębów mlecznych i zębów pierwszych trzonowych stałych w badanej grupie dzieci. W celu określenia zależności pomiędzy puw-z a PUW(6)-z dokonano analizy statystycznej przy użyciu współczynnika korelacji liniowej Pearsona.

Wyniki. Frekwencja próchnicy uzębienia mlecznego w badanej populacji wyniosła 81,20\%, a zębów pierwszych trzonowych stałych $9,21 \%$. Średnia liczba puw-z wynosiła 3,89 $\pm 3,09$, a dla zębów pierwszych trzonowych stałych PUW(6)-z - 0,14 \pm 0,52. Stwierdzono dodatnią zależność pomiędzy obecnością zmian próchnicowych w uzębieniu mlecznym a jej występowaniem w zębach pierwszych trzonowych stałych.

Wnioski. Próchnica uzębienia mlecznego (puw-z) jest czynnikiem predysponującym do jej występowania w pierwszych trzonowcach stałych (PUW(6)-z)(statystycznie istotna zależność). Liczba zębów mlecznych (puw-z) z objawami choroby próchnicowej wiąże się z poziomem zagrożenia chorobą w uzębieniu stałym.

Słowa kluczowe: intensywność i frekwencja próchnicy, dzieci 7-letnie, pierwsze stałe zęby trzonowe.

\begin{abstract}
Introduction. Determining the impact of risk factors is fundamental in developing efficient methods for preventing the occurrence of caries both in children and adults.

Aim. To evaluate the relationship between the presence of caries in milk teeth and the development of caries in the first permanent molar teeth of 7 year old children.

Material and methods. The study was performed on the teeth of 2138 children, including 1033 girls and 1105 boys, aged 7 and living in the city of Poznań. In the clinical study the presence and intensity of caries in milk teeth was evaluated and then compared with the caries that appeared in the first molar permanent teeth. On the basis of the data collected, the frequency and intensity (dmft, DMFT(6)) of caries in milk teeth and later in the first permanent molar teeth were calculated. To detect a correlation between dmft and DMFT(6) a statistical analysis of the results was performed and the Pearson coefficient of linear correlation was calculated.

Results. The frequency of caries in milk teeth in the studied population was $81.20 \%$, while in the first molar teeth it was $9.21 \%$. The average puw-z for milk teeth was $3.89 \pm 3.09$, while the average DMFT(6) for permanent molars was $0.14 \pm 0.52$. A positive correlation was found between the presence of caries in milk teeth and the first permanent molars.

Conclusions. The presence of caries in milk teeth (dmft) is a factor conducive to its appearance in the first permanent molars DMFT(6), this correlation is statistically significant. The number of milk teeth with caries (dmft) is positively correlated with the level of risk of this disease in permanent teeth.
\end{abstract}

Keywords: intensity and frequency of caries, 7-year old children, the first permanent molars.

\section{Wstęp}

Współczesna stomatologia w zapobieganiu próchnicy zębów oraz jej następstwom kładzie szczególnie nacisk na eliminację czynników predyspo- nujących do rozwoju tej choroby poprzez wczesne wdrożenie postępowania zapobiegawczo-leczniczego [1-2]. Zidentyfikowano związek prognostyczny dla powstania i rozwoju choroby zarówno 
zachowań prozdrowotnych jak i pewnych wykładników stanu klinicznego jamy ustnej, w tym bakteriologicznych [2].

Między innymi obserwacje wynikające z licznych badań sugerują, że występowanie ubytków próchnicowych w zębach mlecznych stanowić może zagrożenie dla uzębienia stałego, głównie poprzez szerzenie infekcji bakteryjnej. Jak dotąd nie określono jednak, czy znaczenie dla nasilenia choroby ma liczba zębów z objawami próchnicy, czy sama obecność określonych drobnoustrojów [3-5].

\section{Cel}

Określenie wpływu występowania choroby próchnicowej uzębienia mlecznego u dzieci na jej rozwój w zębach pierwszych trzonowych stałych u dzieci 7-letnich.

\section{Materiał i metody}

Badaniem zostało objętych 2138 dzieci 7-letnich (1033 dziewczynki i 1105 chłopców) zamieszkujących środowisko wielkomiejskie; uczniów szkół podstawowych Poznania.

Ocenę kliniczną stanu uzębienia prowadzili lekarze-specjaliści (stomatolodzy dziecięcy) w sztucznym oświetleniu (lampa czołowa) przy użyciu zgłębnika i lusterka dentystycznego według wytycznych Światowej Organizacji Zdrowia dla celów epidemiologicznych [6]. Zgodnie z nimi aktywną chorobę próchnicową diagnozowano w przypadku stwierdzenia wyraźnego rozpadu tkanek zęba lub obecności opatrunku leczniczego. Wszystkie dane odnotowano w specjalnie przygotowanych do tego celu kartach badań.

W oparciu o zebrane dane obliczono: liczbę zębów mlecznych obecnych w jamie ustnej; liczbę wyrzniętych pierwszych trzonowców stałych (,,szóstych”); frekwencje próchnicy dla uzębienia mlecznego i pierwszych zębów trzonowych sta- łych. Ponadto określono liczbę badanych zębów szóstych z PUW(6)-z = 0 i PUW(6)-z > 0 w odniesieniu do nasilenia choroby próchnicowej w uzębieniu mlecznym (puw-z = 0 i puw-z $>0$ ). Intensywność próchnicy uzębienia mlecznego oraz zębów „szóstych” wyrażono średnią liczbą puw-z i PUW(6)-z. Obliczono średnią wartość puw-z w grupie badanych bez objawów choroby próchnicowej w pierwszych trzonowcach stałych (PUW $(6)-z=0)$ oraz z jej objawami $(P U W(6)>0)$, a także średnią wartość PUW(6)-z w grupie dzieci z i bez objawów choroby próchnicowej w uzębieniu mlecznym (puw-z = 0).

Wyniki badań poddano analizie statystycznej przy zastosowaniu współczynnika korelacji liniowej Pearsona w celu ustalenia zależności pomiędzy nasileniem choroby próchnicowej w uzębieniu mlecznym (puw-z), a jej występowaniem w pierwszych trzonowcach stałych (PUW(6)-z).

Warunkiem przystąpienia dzieci do badań było uzyskanie zgody rodziców oraz Komisji Bioetycznej przy Uniwersytecie Medycznym im. Karola Marcinkowskiego w Poznaniu (uchwała nr 466/10).

\section{Wyniki}

Przeprowadzone badania kliniczne wykazały, że u dziewcząt występowało istotnie statystycznie więcej wyrzniętych pierwszych zębów trzonowych stałych niż u chłopców (Tabela 1).

Frekwencja próchnicy uzębienia mlecznego w badanej populacji wyniosła $81,20 \%$, a jej wartości były podobne u obu płci (dziewczęta - 79,57\%, chłopcy - 82,71\%) (Tabela 1).

Występowanie choroby próchnicowej w pierwszych trzonowcach stałych stwierdzono u 9,21\% uczniów, przy czym w większości przypadków $(5,61 \%)$ jej objawy zdiagnozowano u poszczególnych badanych tylko $w$ jednym zębie (Tabela 2).

Tabela 1 Frekwencja i intensywność próchnicy uzębienia mlecznego oraz zębów pierwszych trzonowych stałych

Table 1. Frequency and intensity of caries in milk teeth and the first permanent molars

\begin{tabular}{|c|c|c|c|c|c|c|c|c|c|c|}
\hline \multirow{3}{*}{$\begin{array}{l}\text { Płeć } \\
\text { Sex }\end{array}$} & \multirow{3}{*}{ 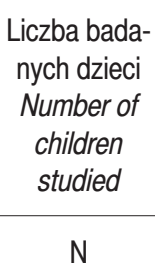 } & \multirow{2}{*}{\multicolumn{3}{|c|}{$\begin{array}{l}\text { Liczba badanych pierwszych } \\
\text { trzonowców stałych } \\
\text { Number of the first perma- } \\
\text { nent teeth }\end{array}$}} & \multicolumn{2}{|c|}{$\begin{array}{l}\text { Frekwencja próchnicy } \\
\text { Frequency of caries }\end{array}$} & \multirow{2}{*}{\multicolumn{2}{|c|}{ PUW-z DMFT }} & \multirow{2}{*}{\multicolumn{2}{|c|}{$\begin{array}{l}\text { PUW(6)-z } \\
\text { DMF(6)T }\end{array}$}} \\
\hline & & & & & \multirow{2}{*}{$\begin{array}{c}\text { Uzębienia } \\
\text { mlecznego } \\
\text { Milk teeth } \\
\%\end{array}$} & \multirow{2}{*}{$\begin{array}{l}\text { Pierwszych trzonowców } \\
\text { stałych } \\
\text { First permanent molars } \\
\%\end{array}$} & & & & \\
\hline & & $\mathrm{n}$ & $\bar{x}$ & SD & & & $\bar{x}$ & $\mathrm{SD}$ & $\bar{x}$ & SD \\
\hline $\begin{array}{l}\text { Dziewczęta } \\
\text { Girls }\end{array}$ & 1033 & 3829 & $3.71^{*}$ & 0.86 & 79.57 & 9.49 & $3.68^{*}$ & 2.98 & 0.16 & 0.56 \\
\hline $\begin{array}{l}\text { Chłopcy } \\
\text { Boys }\end{array}$ & 1105 & 3996 & $3.62^{*}$ & 0.98 & 82.71 & 8.96 & $4.09^{*}$ & 3.17 & 0.13 & 0.47 \\
\hline $\begin{array}{c}\text { Razem } \\
\text { Total }\end{array}$ & 2138 & 7825 & 3.66 & 0.93 & 81.20 & 9.21 & 3.89 & 3.09 & 0.14 & 0.52 \\
\hline
\end{tabular}

* różnica istotna statystycznie

* statistically significant difference 
Intensywność próchnicy w uzębieniu mlecznym (puw-z) równała się 3,89 $\pm 3,09$; stwierdzono istotnie statystycznie wyższą jej wartość u chłopców $(4,09 \pm 3,17)$ w porównaniu z dziewczętami $(3,68 \pm$ 2,98). Średnia liczba PUW(6)-z osiągnęła wartość $0,14 \pm 0,52$, bez występowania istotnych różnic ze względu na płeć dziecka (Tabela 1).

U zdecydowanej większości badanych dzieci $(72,40 \%)$ objawy choroby próchnicowej obserwowano tylko w zębach mlecznych (puw-z $>0$ i PU$W(6)-z=0)$. Odsetek dzieci ze zdrowym uzębieniem mlecznym (puw-z = 0), u których stwierdzono objawy próchnicy w zębach „szóstych” (PUW(6) $-z>0)$ wynosił $0,42 \%$. Próchnicę występującą jednocześnie $w$ uzębieniu mlecznym (puw-z $>0$ ) oraz $w$ zębach pierwszych trzonowych stałych (PUW(6)-z > 0) odnotowano u $8,80 \%$ badanych (Rycina 1).
Badania wykazały, że średnia wartość puw-z u badanych bez objawów choroby próchnicowej w zębach pierwszych trzonowych stałych (PU$W(6)-z=0)$ była istotnie statystycznie niższa od występującej w grupie dzieci z jej objawami (PU$W(6)-z>0$ ), odpowiednio: $3,77 \pm 3,05$ i 5,51 $\pm 2,97$.

Uwzględniając nasilenie choroby próchnicowej w uzębieniu mlecznym badanych podzielono na 3 grupy: puw-z $=0$, puw- $z=1-3$ i puw- $z \geqslant 4$, w których obliczono średnie wartości PUW(6)-z. Stwierdzono występowanie istotnie statystycznie wyższej wartości PUW(6)-z w grupie badanych z puw- $z \geqslant 4(0,21$ $\pm 0,63)$ w porównaniu do badanych $z$ puw- $z=1-3$ $(0,10 \pm 0,39)$ i puw $-z=0(0,03 \pm 0,21)$ (Tabela 3).

Analiza statystyczna wykazała występowanie dodatniej zależności pomiędzy intensywnością choroby próchnicowej w uzębieniu mlecznym (puw-z $>0$ ) a liczbą zębów pierwszych trzonowych stałych z jej objawami (PUW(6)-z > 0).

Tabela 2. Badani z objawami choroby próchnicowej w zębach pierwszych trzonowych stałych

Table 2. Number of children studied with symptoms of caries in the first permanent molars

\begin{tabular}{|c|c|c|c|c|c|c|c|c|c|c|c|c|c|}
\hline \multirow{3}{*}{$\begin{array}{l}\text { Płeć } \\
\text { Sex }\end{array}$} & \multirow{3}{*}{$\begin{array}{l}\text { Liczba } \\
\text { badanych } \\
\text { dzieci } \\
\text { Number of } \\
\text { children } \\
\text { studied }\end{array}$} & \multirow{2}{*}{\multicolumn{2}{|c|}{$\begin{array}{c}\text { Liczba badanych } \\
\text { z PUW }(6)=0 \\
\text { Number of chil- } \\
\text { dren studied with } \\
\text { DMF }(6)=0\end{array}$}} & \multicolumn{10}{|c|}{$\begin{array}{l}\text { Liczba badanych z pierwszymi objawami choroby próchnicowej w trzonowcach stałych } \\
\text { Number of children studied with the symptoms of caries in the first permanent molars }\end{array}$} \\
\hline & & & & \multicolumn{2}{|c|}{$\begin{array}{l}\operatorname{PUW}(6)=1 \\
\operatorname{DMF}(6)=1\end{array}$} & \multicolumn{2}{|c|}{$\begin{array}{l}\operatorname{PUW}(6)=2 \\
\operatorname{DMF}(6)=2\end{array}$} & \multicolumn{2}{|c|}{$\begin{array}{l}\operatorname{PUW}(6)=3 \\
\operatorname{DMF}(6)=3\end{array}$} & \multicolumn{2}{|c|}{$\begin{array}{l}\operatorname{PUW}(6)=4 \\
\operatorname{DMF}(6)=4\end{array}$} & \multicolumn{2}{|c|}{$\begin{array}{c}\text { Razem } \\
\text { Total }\end{array}$} \\
\hline & & $\mathrm{N}$ & $\%$ & $\mathrm{~N}$ & $\%$ & $\mathrm{~N}$ & $\%$ & $\mathrm{~N}$ & $\%$ & $\mathrm{~N}$ & $\%$ & $\mathrm{~N}$ & $\%$ \\
\hline $\begin{array}{l}\text { Dziewczęta } \\
\quad \text { Girls }\end{array}$ & 1033 & 935 & 90.51 & 52 & 5.03 & 32 & 3.11 & 7 & 0.68 & 7 & 0.68 & 98 & 9.49 \\
\hline $\begin{array}{l}\text { Chłopcy } \\
\text { Boys }\end{array}$ & 1105 & 1006 & 91.04 & 68 & 6.15 & 23 & 2.08 & 4 & 0.36 & 4 & 0.36 & 99 & 8.96 \\
\hline $\begin{array}{l}\text { Razem } \\
\text { Total }\end{array}$ & 2138 & 1941 & 90.79 & 120 & 5.61 & 55 & 2.57 & 11 & 0.51 & 11 & 0.51 & 197 & 9.21 \\
\hline
\end{tabular}

Tabela 3. Intensywność choroby próchnicowej w zębach pierwszych trzonowych stałych (PUW(6)-z) w odniesieniu do jej występowania w uzębieniu mlecznym (puw-z)

Table 3. Intensity of caries in the first permanent teeth (PUW(6)-z) in relation to the presence of caries in milk teeth (puw-z)

\begin{tabular}{|c|c|c|c|c|c|c|c|}
\hline \multirow{3}{*}{$\begin{array}{l}\text { Płeć } \\
\text { Sex }\end{array}$} & \multirow{3}{*}{$\begin{array}{c}\text { Liczba badanych } \\
\text { dzieci } \\
\text { Number of chil- } \\
\text { dren studied }\end{array}$} & \multicolumn{6}{|c|}{$\begin{array}{c}\text { Średnia liczba PUW(6)-z w pierwszych trzonowcach stałych przy: } \\
\text { Average PUW(6)-z in the first permanent molars at }\end{array}$} \\
\hline & & \multicolumn{2}{|c|}{$\begin{array}{l}\text { puw-z }=0 \\
\mathrm{dmft}=0\end{array}$} & \multicolumn{2}{|c|}{$\begin{array}{c}\text { puw- } z=1-3 \geqslant 0 \\
\text { dmft }=1-3 \geqslant 0\end{array}$} & \multicolumn{2}{|c|}{$\begin{array}{l}\text { puw }-z \geqslant 4 \\
\mathrm{dmft} \geqslant 4\end{array}$} \\
\hline & & $\bar{x}$ & SD & $\bar{x}$ & SD & $\bar{x}$ & SD \\
\hline $\begin{array}{l}\text { Dziewczęta } \\
\text { Girls }\end{array}$ & 1033 & 0.03 & 0.23 & 0.12 & 0.46 & 0.24 & 0.70 \\
\hline $\begin{array}{c}\text { Chłopcy } \\
\text { Boys }\end{array}$ & 1105 & 0.03 & 0.19 & 0.07 & 0.31 & 0.19 & 0.58 \\
\hline $\begin{array}{c}\text { Razem } \\
\text { Total }\end{array}$ & 2138 & $0.03^{*}$ & 0.21 & $0.10^{*}$ & 0.39 & $0.21^{*}$ & 0.63 \\
\hline
\end{tabular}

* różnica istotna statystycznie

* statistically significant difference 


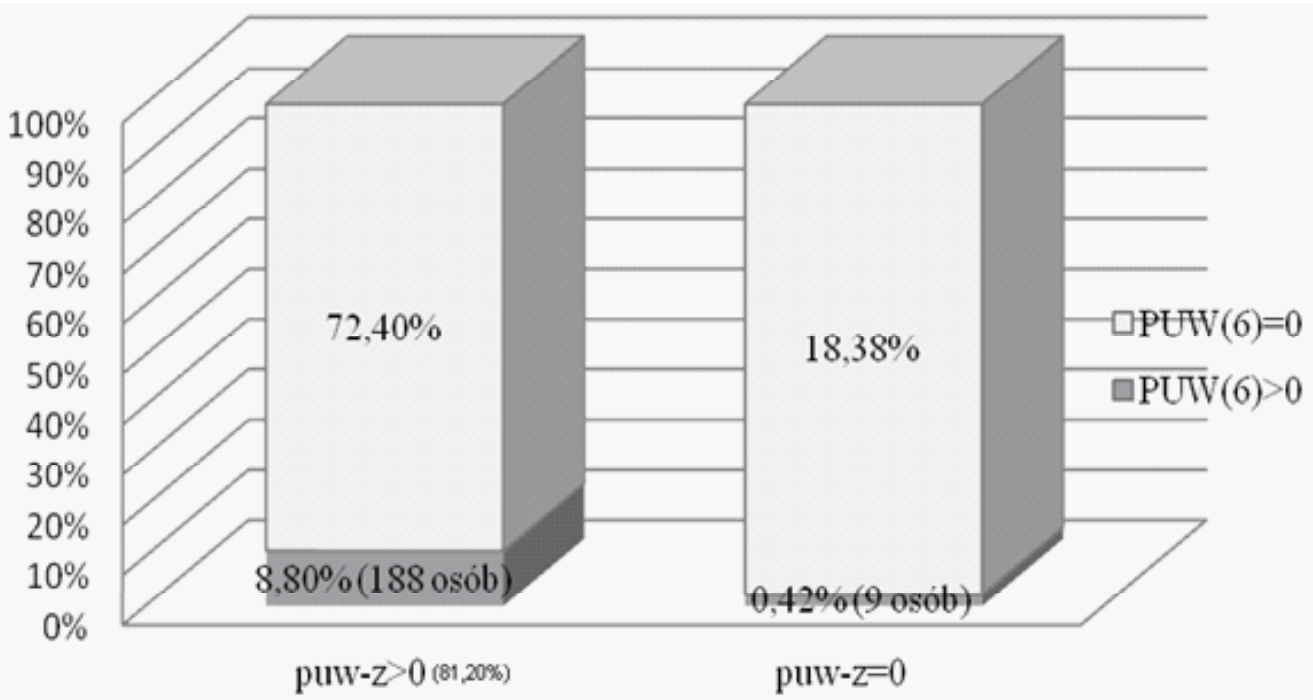

Rycina 1. Odsetek badanych z objawami choroby próchnicowej w uzębieniu mlecznym i w zębach pierwszych trzonowych stałych

Figure 1. Percentage of the children studied showing symptoms of caries in milk teeth and in the first permanent molars

\section{Omówienie}

Dane WHO z 2012 roku mówią o występowaniu choroby próchnicowej prawie u 100\% dorosłych oraz u 60-90\% populacji dzieci na świecie [7]. W Polsce choroba próchnicowa zaliczana jest także do chorób społecznych, a na tle innych państw Europy jej frekwencja u dzieci osiąga od wielu lat jedne z najwyższych wartości. Przeprowadzone w 2011 roku w ramach Ogólnopolskiego Monitoringu Zdrowia Jamy Ustnej badania wykazały wysokie wartości frekwencji i intensywności próchnicy uzębienia u poznańskich 7-latków - odpowiednio $83,1 \%$ dla uzębienia mieszanego przy PUW-z = 0,19 oraz puw-z $=4,58[8,9]$. Porównywalnie do polskiej populacji 7-latków zamieszkujących duże miasto, wysokie odsetki frekwencji próchnicy stwierdza się również u 7-8-latków z Litwy 85,5\%. [10]. Próchnicę uzębienia mlecznego u zamieszkujących Federację Rosyjską odnotowuje się aż u 93,7\% dzieci w omawianej grupie wieku [11].

$\mathrm{W}$ badaniach własnych $\mathrm{u}$ dziewcząt odnotowano istotnie statystycznie więcej wyrzniętych pierwszych trzonowców stałych niż u chłopców, co potwierdziło dane $z$ monitoringu dla Polski (u dziewcząt 3,73, u chłopców 3,52). Podobnie jak u poznańskich 7-latków dane z monitoringu wskazały na podobne wartości intensywności próchnicy w uzębieniu mlecznym u chłopców $(5,74)$ w porównaniu do dziewcząt $(5,51)$, jak i stałym: 0,57 u dziewcząt i 0,55 u chłopców. U dziewcząt wyższa średnia liczba wyrzniętych zębów stałych trzonowych oraz nieco wyższe wartości intensywności próchnicy uzębienia stałego mogą sugerować wcześniejsze drugie ząbkowanie u dziewczynek, co tworzy warunki do dłuższej ekspozycji bakterii próchnicotwórczych.
Niepokojący jest fakt objęcia chorobą próchnicową pierwszych trzonowców stałych $w$ tak krótkim czasie po ich wyrznięciu, aż u 9,21\% badanych. Jest to wyraźnie niższy odsetek w porównaniu z danymi uzyskanymi w 1998 roku przez Kruszyńską-Rosadę i wsp. dotyczącymi dzieci w wieku 7-8 lat. Cytowani autorzy zdiagnozowali ubytki w zębach pierwszych trzonowych stałych u 45,29\% 7-latków i 62,8\% 8-latków [3].

Koncepcje współczesnej stomatologii zakładają bardziej indywidualne, ukierunkowane postępowanie profilaktyczno-lecznicze w zależności od zdiagnozowanych potrzeb oraz wskazań. Kładzie się nacisk na wyłanianie grup osób najbardziej narażonych, a następnie opracowanie i wdrażanie u nich działań zapobiegawczych [1, 2].

Wielu badaczy udowodniło, że występowanie choroby próchnicowej w uzębieniu mlecznym jest czynnikiem ryzyka wpływającym na zdrowie uzebienia stałego. Szafrańska-Perkowska B. i Waszkiel D. przeprowadzając badania wśród dzieci 7-letnich na terenie Białegostoku potwierdziły zależność pomiędzy występowaniem choroby próchnicowej w uzębieniu mlecznym i pierwszych trzonowcach stałych. Autorki wykazały, że wraz ze wzrostem liczby powierzchni zębów trzonowych mlecznych objętych próchnicą ulega wzrostowi liczba dzieci z objawami choroby w zębach „szóstych” [4]. Również badania Asli Topaloglu-Ak i Ece Eden u dzieci 6-7-letnich z Turcji udowodniły występowanie statystycznie istotnej korelacji pomiędzy dmft uzębienia mlecznego a DMFT zębów pierwszych trzonowych stałych [12]. Długoterminowe badania Skeie i wsp., przeprowadzone na grupie norweskich dzieci, dowiodły, że istotnym czynnikiem prognostycznym objawów cho- 
roby próchnicowej w zębach stałych jest istnienie więcej niż dwóch powierzchni objętych próchnicą w drugich trzonowcach mlecznych $u$ tych samych dzieci w wieku 5 lat. Autorzy podkreślają, że wskaźnik dmf-s może prognozować pojawienie się próchnicy nie tylko na powierzchniach mezjalnych pierwszych trzonowców stałych, ale i w siekaczach stałych, jak również licznych zmian próchnicowych w pozostałych grupach zębowych uzębienia stałego [5]. Także badania Augustyniak M. dowodzą, że stan zdrowia zębów pierwszych trzonowych stałych prognozuje stan całego uzębienia stałego [13].

W badaniach własnych również wykazano dodatnią zależność pomiędzy nasileniem choroby próchnicowej w uzębieniu mlecznym (puw-z) a jej obecnością w pierwszych trzonowcach stałych (PUW(6)-z). Poza tym uzyskane wyniki mówią o występowaniu istotnie statystycznie wyższych wartości średniego PUW(6)-z u badanych z puw$-z \geqslant 4$ w porównaniu do badanych $z$ puw $-z=1-3$ oraz puw-z $=0$. Sugeruje to, że dzieci, u których więcej niż 4 zęby mleczne objęte są procesem próchnicowym można uważać za grupę wysokiego ryzyka.

Należy odnotować, że u $0,42 \%$ badanych 7-latków, pomimo braku występowania choroby w uzębieniu mlecznym (puw-z $=0$ ), jej objawy stwierdzono w zębach „szóstych” (PUW(6)-z > 0). Dla porównania, Kruszyńska-Rosada i wsp. w przytaczanych wcześniej badaniach próchnicę występującą tylko w zębach pierwszych trzonowych stałych zdiagnozowali u 3,24\% uczniów [3]. Jak komentują tę obserwację inni autorzy, być może odpowiedzialność należy przypisać innym czynnikom niż bakteryjny. W początkowym etapie edukacji szkolnej dziecko trafia do nowego otoczenia, w którym często panują niewłaściwe nawyki dietetyczne. Zmniejszona kontrola rodziców sprawia, że łatwiejszy staje się dostęp do słodkich przekąsek oraz napojów obecnych w szkolnych sklepikach. Dostarczanie próchnicotwórczych węglowodanów oraz współwystępowanie czynnika infekcyjnego tworzą warunki wzmożonego zagrożenia chorobą także dla tych uczniów [14].

U dzieci w wieku 7 lat możliwa jest też pierwotna kolonizacja paciorkowcami próchnicotwórczymi, których źródłem są rówieśnicy uczęszczający do tej samej szkoły, czyli tak zwana transmisja horyzontalna [15]. Biorąc pod uwagę, że drugie ząbkowanie rozpoczyna się najczęściej od wyrznięcia pierwszych trzonowców, oraz to, że najwcześniej są one usuwane $z$ powodu powikłań próchnicy, działania prewencyjne powinny być wdrażane jeszcze przed ich pojawieniem się w jamie ustnej dziecka [16]. Proponowane programy profilaktyczne powinny uwzględniać oprócz edukacji prozdrowotnej (poprzedzonej wyleczeniem zębów i poprawą zachowań zdrowotnych), także eliminację czynnika infekcyjnego ze strony uzębienia mlecznego, a następnie odpowiednio wczesną izolację bruzd świeżo wyrzniętych pierwszych trzonowców stałych.

\section{Wnioski}

1. Istnieje dodatnia zależność pomiędzy nasileniem próchnicy uzębienia mlecznego (puw-z) a jej występowaniem w zębach pierwszych trzonowych stałych (PUW(6)-z). Liczba zębów mlecznych (puw-z) z objawami choroby próchnicowej wiąże się z poziomem zagrożenia chorobą w uzębieniu stałym.

2. Wyniki badań wskazują na stosunkowo wysoka frekwencję i intensywność próchnicy w tej populacji, co potwierdza dane o złym stanie uzębienia najmłodszych dzieci w Polsce.

\section{Oświadczenia}

\section{Oświadczenie dotyczące konfliktu interesów}

Autorzy deklarują brak konfliktu interesów w autorstwie oraz publikacji pracy.

\section{Źródła finansowania}

Autorzy deklarują brak źródeł finansowania.

\section{Piśmiennictwo}

[1] Wierzbicka M. Określenie profilu ryzyka próchnicy. Standard diagnozowania ryzyka i zapobiegania próchnicy zębów w praktyce lekarza dentysty. Fundacja Promocji Zdrowia Jamy Ustnej. Warszawa 2006; 6-20

[2] American Academy of Pediatric Dentistry. Council on Clinical Affairs. Guideline on caries-risk assessment and management for infants, children and adolescents. 2011/2012;33(6):110-117.

[3] Kruszyńska-Rosada M, Żurowski M, Lempe B. Występowanie próchnicy w mlecznych i stałych zębach trzonowych u dzieci w wieku 7 i 8 lat. Pozn Stomatol. 1998;137141.

[4] Szafrańska-Perkowska B, Waszkiel D. Intensywność próchnicy zębów mlecznych a stan zębów szóstych u 7-letnich dzieci białostockich. Porad Stomatol. 2004;12:31-35.

[5] Skeie MS, Raadal M, Strand GV, Espelid I. The relationship between caries in the primary dentition at 5 years of age and permanent dentition at 10 years of age - a longitudinal study. Int J Paediatr Dent. 2006;16:152-160.

[6] Oral Health Surveys, Basic Data. WHO, Geneva 1997.

[7] www.who.int. Oral Health. Fact sheet 318. April 2012.

[8] Wierzbicka M. i wsp. Monitoring Zdrowia Jamy Ustnej. Polska 2011.

[9] Wierzbicka M, Strużycka I, Szatko F, Ganowicz M. Zdrowie jamy ustnej w Polsce na przełomie pierwszej i drugiej dekady XXI wieku. Stomatol Współcz. 2012;19(3):8-16.

[10] Saldūnaite K, Pūriene A, Milciuviene S, Brukiene V, Kutkauskiene J. Analysis of dental caries preventionLi Y, Wang W. Predicting caries in permanent teeth from caries in primary teeth; an eight-year cohort study. J. Dent. Res., 2002;81(8):561-566. program in 7-12-year-old Lithuanian schoolchildren. Medicina (Kaunas). 2009;45(11):887-895.

[11] Chuprunova IN, Kosyuga SYu, Pyatova ED, Krivulina GV. Caries prevalence and incidence in 7-year-old children of Nizhny Novgorod. Stomatol. 2010;2:4-6.

[12] Topaloglu-Ak A, Eden E. Caries in primary molars of 6-7-year-old Turkish children as risk indicators for future caries development in permanent molars. J Dent Sci. 2010;5(3):150-155. 
[13] Augustyniak M. Stan pierwszych zębów trzonowych stałych jako czynnik prognostyczny stanu narządu żucia u dzieci i młodzieży powiatu pilskiego. Rozprawa doktorska. Poznań 2010

[14] Kaczmarek U. Aspekt bakteryjny próchnicy zębów mlecznych. Dent Med Probl. 2004;41(3):509-514.

[15] Baca P, Castillo AM, Liébana MJ, Castillo F, Martín-Platero A, Liébana J. Horizontal transmission of Streptococcus mutans in schoolchildren. Med Oral Patol Oral Cir Bucal. 2012;17(3):495-500.

[16] Hilt A. Ząb pierwszy trzonowy stały - stan i potrzeby lecznicze na podstawie badań epidemiologicznych i klinicznych u dzieci w wieku 7, 12, 18 lat. Rozprawa doktorska. Łódź 2000.
Zaakceptowano do edycji: 2016-04-28 Zaakceptowano do publikacji: 2016-05-06

Adres do korespondencji:

Katedra i Klinika Stomatologii Dziecięcej

Uniwersytet Medyczny im. Karola Marcinkowskiego

w Poznaniu

ul. Bukowska 70, 60-812 Poznań

tel.: 618547053

fax: 618547059

e-mail: joannachlapowska@wp.pl 